\title{
A "Visão Histórica da Psicologia Social" de Ignacio Martín-Baró
}

\author{
Filipe Boechat* \\ Universidade Federal do Rio de Janeiro - UFRJ, Rio de Janeiro, RJ, Brasil \\ ORCID: http://orcid.org/0000-0002-2447-0774 \\ André Vieira** \\ Centro Universitário IBMR, Rio de Janeiro, RJ, Brasil \\ ORCID: https://orcid.org/0000-0002-0975-0188 \\ Bruno Pizzi**** \\ Universidade Federal da Grande Dourados - UFGD, Dourados, MS, Brasil \\ ORCID: https://orcid.org/0000-0002-4379-3974
}

\begin{abstract}
RESUMO
O presente artigo resulta da análise imanente da "visão histórica da Psicologia Social" desenvolvida por Ignacio Martín-Baró nos dois volumes de sua Psicología Social desde Centroamerica: o volume intitulado Acción y ideología (1983) e aquele intitulado Sistema, grupo y poder (1989). Apresenta, de forma sintética, os principais aspectos de sua interpretação historiográfica, pouco conhecida e discutida. Mostramos que, para Martín-Baró, a história da Psicologia Social não deve ignorar a importância da reflexão filosófica para a pesquisa histórica; deve reconhecer a importância, para a pesquisa histórica, dos clássicos da teoria social e política; pressupõe o vínculo dialético entre o conhecimento científico e as crises sociais; encontra-se dialeticamente subordinada à história social e política; não conhece um desenvolvimento linear e cumulativo; permite a justaposição de teorias oriundas de problemáticas distintas; insere-se no movimento de surgimento das ciências humanas e sociais; pressupõe um movimento de crítica e de libertação da Psicologia; deve assumir a perspectiva dos oprimidos se ela deseja contribuir para seu processo de emancipação; deve manter uma relação crítica com a perspectiva positivista e pragmatista da ciência; deve criticar o individualismo, o psicologismo, o subjetivismo e o elitismo; não pode contentar-se com uma compreensão limitada e negativa do conceito de crise.
\end{abstract}

Palavras-chave: Ignacio Martín-Baró, história da psicologia, história social da psicologia, história da psicologia social, psicologia social.

\section{Ignacio Martín-Baró's "Historical View of social Psychology"}

\begin{abstract}
This article results from the immanent analysis of the "historical view of Social Psychology" developed by Ignacio Martín-Baró in the two volumes of his Psicología Social desde Centroamerica: the volume entitled Acción e ideología (1983) and the volume entitled Sistema, grupo y poder (1989). It presents, in a synthetic way, the main aspects of his historiographic interpretation, still little known and discussed. We show that, for Martín-Baró,
\end{abstract}


the history of Social Psychology must not ignore the importance of philosophical reflection for historical research; it must recognize the importance of the classics of social and political theory for historical research; it presupposes the dialectical link between scientific knowledge and social crises; it is dialectically subordinated to social and political history; does not know a linear and cumulative development; allows the juxtaposition of theories from different problematics; is part of the human and social sciences' emergence movement; it presupposes a movement of criticism and liberation from Psychology; it must take the perspective of the oppressed if it wishes to contribute to its emancipation process; it must maintain a critical relationship with the positivist and pragmatist perspective of science; it must criticize individualism, psychologism, subjectivism and elitism; It cannot be content with a limited and negative understanding of the concept of crisis.

Keywords: Ignacio Martín-Baró, history of psychology, social history of psychology, history of social psychology, social psychology.

\section{La "Visión Histórica de la Psicología Social" de Ignacio Martín-Baró}

\section{RESUMEN}

Este artículo es el resultado del análisis inmanente de la "visión histórica de la psicología social" desarrollada por Ignacio Martín-Baró en los dos volúmenes de su Psicología Social desde Centroamerica: el volumen titulado Acción e ideología (1983) y el volumen titulado Sistema, grupo y poder (1989). Presenta, de manera sintética, los principales aspectos de su interpretación historiográfica, aún poco conocidos y discutidos. Mostramos que, para MartínBaró, la historia de la psicología social no debe ignorar la importancia de la reflexión filosófica para la investigación histórica; debe reconocer la importancia, para la investigación histórica, de los clásicos de la teoría social y política; presupone el vínculo dialéctico entre el conocimiento científico y las crisis sociales; está dialécticamente subordinado a la historia social y política; no conoce un desarrollo lineal y acumulativo; permite la yuxtaposición de teorías de diferentes problemáticas; es parte del movimiento por el surgimiento de las ciencias humanas y sociales; presupone un movimiento de crítica y liberación de la psicología; debe tomar la perspectiva de los oprimidos si desea contribuir a su proceso de emancipación; debe mantener una relación crítica con la perspectiva positivista y pragmática de la ciencia; debe criticar el individualismo, el psicologismo, el subjetivismo y el elitismo; no puede contentarse con una comprensión limitada y negativa del concepto de crisis.

Palabras clave: Ignacio Martín-Baró, historia de la psicología, historia social de la psicología, historia de la psicología social, psicología social.

A história da Psicologia é um campo minado. Em História da Psicologia: um panorama e avaliação crítica, Hilgard, Leary e McGuire (1998) elencaram algumas das questões que costumam transformar esse campo de estudos, aparentemente calmo, num verdadeiro campo de batalhas. De acordo com os autores (Hilgard et al., 1998, p. 410), 
Dentre as muitas questões historiográficas que têm preocupado os historiadores da psicologia durante as décadas passadas, talvez as mais importantes e úteis sejam aquelas que giram em torno de (a) continuidade vs. descontinuidade; (b) presentismo vs. historicismo; (c) internalismo vs. externalismo; (d) "grandes homens" vs. "o Zeitgeist"; e (e) a legitimação cerimonial vs. a história crítica.

No que tange à história da Psicologia Social, não tem sido diferente. Afinal, aí também as historiadoras e os historiadores têm divergido quanto à continuidade e a descontinuidade da história; quanto à relação que o passado estabelece com os problemas e as categorias do presente; quanto ao grau de autonomia que a Psicologia Social possui em relação às demais ciências e à sociedade de que faz parte; quanto à importância do indivíduo na história e no desenvolvimento da Psicologia Social ou quanto ao peso da cultura nesse mesmo desenvolvimento; quanto à função social e epistemológica do conhecimento histórico ou, melhor dizendo, se a história deve prestar-se à legitimação e à justificação da Psicologia Social ou se, ao contrário, deve estar a serviço da crítica teórica e prática de seus pressupostos ideológicos e sociomateriais.

No entanto, apesar de sua flagrante diversidade e da variedade das divergências que comporta, a história da Psicologia Social ainda costuma ser contada a partir de critérios exclusivamente cronológicos, em narrativas apologéticas que estabelecem séries contínuas e lineares de grandes ideias veiculadas por "grandes homens" (nem sempre grandes, mas sempre homens) aparentemente destacados de seu próprio tempo histórico.

Em Historicizar para libertar: a proposta de Psicologia da Libertação (2018), Lacerda Jr. fez semelhante observação. De acordo com o autor,

Na Psicologia Social ocorre o mesmo [que na Psicologia]: alguns manuais apresentam uma História cronológica, na qual a sucessão de correntes e perspectivas parece se dar temporalmente, como se houvesse um permanente processo de ascensão, hegemonia e queda de certos conceitos ou teorias que, em seguida, são sucedidos por outros conceitos e teorias que, também, ascendem, se tornam hegemônicos e, em algum momento, se tornarão marginais. (Lacerda Jr., 2018, pp. 74)

Nesse mesmo texto, em que defende a contribuição da Psicologia da Libertação para o desenvolvimento de uma Histórica Social da Psicologia, Lacerda Jr. apresentou-nos uma 
interpretação bastante diferente da forma hegemônica como vem sendo escrita a história da Psicologia Social. Original e ainda pouco conhecida, trata-se da interpretação esboçada por Ignacio Martín-Baró (1942-1989) em Acción y ideología, primeiro volume de sua Psicología Social desde Centroamerica, publicado em 1983.

Em sua argumentação, Lacerda Jr. lançou mão de uma longa passagem do primeiro capítulo de Acción y ideología onde Martín-Baró esboçara, segundo suas próprias palavras, uma "visão histórica da Psicologia Social” (Martín-Baró, 1985/2015, p. 27). No presente artigo, buscamos avançar na trilha aberta por Lacerda Jr. (2018), incorporando às considerações históricas realizadas por Martín-Baró em Acción y ideología aquelas realizadas pelo autor, em 1989, no volume Sistema, grupo y poder, segundo dos dois volumes dessa que constitui, na opinião de alguns de seus comentadores (De La Corte, 2001; Dobles, 2016; Lacerda Jr., 2017), a obra que melhor sintetiza sua Psicologia Social. Assim, o presente artigo resulta da leitura e análise imanentes da "visão histórica da Psicologia Social" desenvolvida por Ignacio Martín-Baró nos dois volumes de sua Psicología Social desde Centroamerica, quais sejam: Acción y ideología e Sistema, grupo y poder.

$\mathrm{O}$ artigo busca apresentar, de forma sintética, os principais aspectos de sua interpretação historiográfica, ainda pouco conhecida e discutida no Brasil. Para tanto, recorre ao método da leitura e análise imanentes (Costa, 2009; Lessa, 2014), uma vez que, conforme observou Lessa (2014, p. 69), "Quando se trata de precisar as concepções de qualquer autor, é imperioso que se conceda a mais rigorosa prioridade ao texto.” Aliás, gostaríamos de advertir que as numerosas citações ao longo do artigo decorrem da opção metodológica pela leitura e análise imanentes, nas quais buscamos, tanto quanto possível, mantermo-nos o mais próximo possível da letra do texto analisado. Não se quer, com isso, sugerir que a leitura imanente esgote seu sentido. Mesmo porque, como assinalou Costa, "a investigação imanente de um texto, por maior valor que tenha sido o esforço acadêmico empreendido, não esgota a interpretação do texto, fazendo-se necessário atentar para o seu papel social na referência ao momento histórico de sua gênese" (Costa, 2009, p. 32). Apenas desejamos, tanto quanto possível, deixar que fale o próprio autor.

Já a opção pelos dois volumes de Psicología Social desde Centroamerica decorre do fato de que foi aí que Martín-Baró realizou a síntese das inúmeras reflexões realizadas entre as décadas de 1970 e 1980. Afinal, como nos relevou Lacerda Jr., referindo-se ao volume Acción y ideología, 
A primeira edição do livro foi publicada em 1983. Mas há diversos indicadores de que foi um trabalho preparado ao longo da segunda metade da década de 1970. Em primeiro lugar, há dois rascunhos do livro, Lecturas de Psicología Social (1975) e Psicología Social (1976), que contêm esboços e, em boa medida, repetem a mesma estrutura do livro que foi publicado em 1983. Além disso, na biblioteca da UCA é possível encontrar pequenos fascículos publicando partes do material que, em 1983, apareceria reunido no livro. (Lacerda Jr., 2017, p. 13)

Sistema, grupo y poder, por sua vez, foi publicado exatamente no ano do assassinato de Martín-Baró, constituindo forte expressão de seu acúmulo teórico ${ }^{1}$. Aliás, vale notar que, aqui também, há indicadores de que o volume resulta de pequenos trabalhos desenvolvidos previamente pelo autor. Pois, conforme pudemos observar nas referências bibliográficas do artigo Los grupos con historia: un modelo psicosocial (Martín-Baró, 1992, p. 29), MartínBaró menciona duas publicações provisórias que contém, em seu conjunto, o temário de Sistema, grupo y poder: a saber, Sistema y poder (1984) e Psicología social de grupos (1986).

$\mathrm{Na}$ seção seguinte, analisaremos a história da Psicologia Social desenvolvida por Martín-Baró em Acción y ideología. Depois, a interpretação apresentada pelo autor em Sistema, grupo y poder. Por fim, antes de passarmos às considerações finais, apresentaremos os principais aspectos de sua "visão histórica de Psicologia Social", na esperança de contribuirmos, por pouco que seja, para a ampliação do conhecimento a respeito da interpretação martinbaroniana da história da Psicologia Social e para os ainda escassos estudos de sua obra no Brasil. Afinal, como alertou Lacerda Jr.,

Martín-Baró ainda não foi devidamente estudado pela Psicologia brasileira. Apesar de existirem referências à importância de sua obra e trabalhos relacionando partes de sua obra com certos campos específicos (especialmente a Psicologia Política, a Psicologia Comunitária e a Psicologia social), a presença de sua obra é marginal nos cursos de graduação e pós-graduação em Psicologia. (Lacerda Jr., 2017, pp. 14)

\section{Uma “Visão Histórica da Psicologia Social” em Acción y Ideología}

Em seu primeiro livro, Psicodiagnóstico de América Latina (1972), Martín-Baró já revelava sua convicção quanto à necessidade de colocar o conhecimento psicológico a serviço da resolução dos problemas enfrentados pelos povos latino-americanos. Apesar, porém, da 
disposição de colocar a psicologia "contra a ordem” (Lacerda Jr., 2017) já estar presente no início da década de 1970, foi apenas com a publicação de Acción y ideología, em 1983, que Martín-Baró evidenciou, de maneira mais rigorosa e sistemática, sua compreensão de que o desenvolvimento de uma Psicologia da Libertação supõe um movimento prévio de crítica e de libertação da Psicologia e que esse movimento pressupõe, acima de tudo, o recurso à história e uma nova compreensão da história da Psicologia Social.

É verdade que o volume, dividido em oito capítulos, ainda obedece à estrutura clássica dos grandes manuais de Psicologia Social: principia com considerações gerais de natureza histórica e teórico-metodológica, antes de passar ao exame de fenômenos psicossociais particulares ${ }^{2}$. Entretanto, embora relativamente conservador em sua forma, o volume lança mão de recursos gráficos inovadores e aborda temas originais quando comparado aos grandes manuais de Psicologia Social estadunidenses (Freedman, Carlsmith, \& Sears, 1977; Lindzey \& Aronson, 1968, 1985). Tortura, greves e problemas habitacionais são aí ilustrados e teoricamente tratados, revelando desde logo a preocupação do autor para com o conjunto de problemas colocados pelo contexto social, político e econômico salvadorenho e, de maneira mais geral, com a situação de opressão, exploração, miséria e desigualdade dos países centroamericanos. Aliás, é o próprio autor quem nos alerta, no prólogo escrito em abril de 1983, que seu objetivo, com a publicação de Acción y ideología, consistiu em "articular a perspectiva dos condenados desta terra centroamericana com o trabalho da psicologia social como ciência e como práxis" e que, por isso mesmo, "o critério definitivo sobre o valor desta obra não pode traduzir-se em seu rigor convencional ou sua coerência em nível abstrato, mas em sua contribuição efetiva, por pequena que seja, ao processo de libertação dos povos centroamericanos” (Martín-Baró, 1985/2015, p. 32, tradução livre ${ }^{3}$ ).

De fato, já no primeiro capítulo, intitulado Entre o indivíduo e a sociedade, vemos o autor empreender uma crítica radical dos fundamentos histórico-ideológicos da Psicologia Social de seu tempo. Vemos, além disso, que parte substantiva dessa crítica consiste, precisamente, na apresentação de "uma visão histórica da Psicologia Social" (Martín-Baró, 1985/2015, p. 27-46), sobre a qual concentraremos, a partir de agora, nossa atenção. Propondo uma periodização bastante original, Martín-Baró organizou a história da Psicologia Social com base em três questões fundamentais. Assim se expressou o autor:

Com o fim de abarcar significativamente a evolução da Psicologia Social contemporânea, podemos sintetizar sua história em três períodos que foram caracterizados pelo predomínio de três perguntas ou perspectivas fundamentais. (1) O 
que mantém as pessoas unidas na ordem social estabelecida? (2) O que integra as pessoas na ordem social? (3) O que liberta as pessoas da desordem estabelecida? (Martín-Baró, 1985/2015, p. 32)

Martín-Baró fez questão de observar que esses períodos não seriam três etapas da história da Psicologia Social, "mas três abordagens fundamentais que ganham corpo em circunstâncias e momentos históricos diferentes e que convivem, como alternativa acadêmica, com os outros enfoques (Martín-Baró, 1985/2015, p. 32). Chamou atenção, também, para a relativa continuidade da história da Psicologia Social em relação à história da filosofia. Resgatando Sócrates, Platão, Maquiavel, Hobbes, Rousseau e Marx (Martín-Baró, 1985/2015, p. 27), insistiu sobre a importância dos clássicos da teoria social e política. Assinalou que o pensamento filosófico teria formulado questões até hoje postas pela Psicologia Social e indicou, ainda, a profunda carência filosófica das pesquisas psicológicas de seu tempo, afirmando que, "após terem desprezado uma longa e rica tradição de filosofia psicológica, alguns psicólogos (sociais e gerais) (...) [chegaram] a conclusões que foram muito melhor elaboradas em tempos passados pela filosofia” (Martín-Baró, 1985/2015, p. 27). Ainda antes de expor sua "visão histórica da Psicologia Social", o autor apresentou elementos decisivos para o surgimento das ciências sociais. Segundo o autor,

Há quatro acontecimentos históricos que devem ser analisados para se compreender as especificidades e o nascimento da Psicologia Social (assim como das ciências sociais) em seu sentido moderno: maior consciência sobre as diferenças entre grupos humanos; concepção secularizada de ser humano; revolução industrial; desenvolvimento de uma nova metodologia. (Martín-Baró, 1985/2015, pp. 29)

Para Martín-Baró, esse primeiro período teria sido marcado pela prevalência da seguinte questão: o que mantém as pessoas unidas na ordem social estabelecida? A pergunta seria o resultado da crise que se abateu sobre a Europa na passagem do século XIX ao século XX como consequência dos processos de industrialização capitalista (Martín-Baró, 1985/2015, p. 33); as respostas, por outro lado, teriam sido as manifestações ideológicas de uma sociedade dividida e em busca de um critério de unificação.

Em geral, a resposta consiste em alguma variante sobre o tema central da "mente grupal”: de uma forma ou de outra, todos os membros de uma mesma sociedade 
participam de algo comum, algo que não é material, mas espiritual, e que os mantém unidos para além de diferenças e interesses individuais. (Martín-Baró, 1985/2015, pp. 33)

Neste período, o autor situou as formulações de Wilhelm Wundt (1832-1920), Émile Durkheim (1858-1917), Max Weber (1864-1920) e Sigmund Freud (1856-1939). Wundt teria se ocupado, em sua Psicologia dos Povos, dos produtos da ação recíproca dos indivíduos; Durkheim, em sua Sociologia positiva, da consciência coletiva, transcendente, coercitiva e irredutível às consciências individuais; Weber, em sua Sociologia compreensiva, da ideologia enquanto subjetivação de interesses objetivos; Freud, em sua Psicologia das massas..., dos processos identificatórios que responderiam pela formação das lideranças políticas.

Segundo Martín-Baró, apesar da diversidade dessas formulações e em que pese os autores em questão não se reconhecerem, à época, como psicólogos sociais, todos teriam pressuposto "a sociedade como um todo comum e unitário que a evolução dos processos históricos pode[ria] colocar em perigo" (Martín-Baró, 1985/2015, p. 34). Além disso, todos teriam buscado "articular as necessidades dos indivíduos com as necessidades da totalidade social” (Martín-Baró, 1985/2015, p. 34). O segundo período da história da Psicologia Social teria sido marcado, por sua vez, pela prevalência da seguinte questão: o que integra as pessoas na ordem social? A questão seria sutilmente diferente da questão prevalente no período anterior. Afinal, de acordo com Martín-Baró,

Se o primeiro período da psicologia social pressupunha como real a unidade da sociedade como um todo homogêneo, este segundo período dá um passo adiante e aceita a ideia de inquestionabilidade da ordem social existente e sob a qual se encontra a totalidade social. (Martín-Baró, 1985/2015, pp. 34)

O período corresponderia à "americanização da psicologia e das ciências sociais em geral" (Martín-Baró, 1985/2015, p. 34), em que a pergunta pela unidade dos indivíduos e dos povos teria dado lugar às exigências imediatas de integração social. Para o autor, "A pergunta funcional sobre o que mantém os membros de uma sociedade unidos se transforma em uma pergunta sobre o que se deve fazer para que qualquer indivíduo ou grupo seja integrado de forma harmoniosa na ordem social existente.” (Martín-Baró, 1985/2015, p. 34). Na base desse período, Martín-Baró situou o movimento de imigração e as profundas mudanças ocorridas nos Estados Unidos no início do século XX. Segundo o autor, "no momento da avalanche 
imigratória, a exigência imediata era a de integrar os recém-chegados à ordem e sistema estabelecidos, de adaptá-los à cultura e estilo de vida dominantes, ou seja, o aculturamento primeiro, a socialização depois" (Martín-Baró, 1985/2015, pp. 35-36). Mas a questão prevalente deste período não teria sido determinada apenas pela questão imigratória. Para o autor, o acelerado processo de industrialização vivido pela sociedade norte-americana, no período entre o fim do século XIX e início do século XX, teria sido igualmente fundamental nesse processo de reconfiguração da Psicologia Social.

De acordo com Martín-Baró, as classes dominantes norte-americanas muito rapidamente teriam reconhecido a importância das ciências sociais no processo de adaptação dos indivíduos à nova ordem mundial. Assim, nesse período, quando os psicólogos se perguntavam o que integrava as pessoas na ordem social, o que buscavam eram mecanismos mais eficientes de adequação dos diversos indivíduos à ordem existente. Importava, acima de tudo, "oferecer respostas práticas aos problemas concretos colocados pela estrutura social dominante" (Martín-Baró, 1985/2015, p. 36).

\begin{abstract}
A busca do máximo de lucro levava também à procura pelo máximo de eficiência, e com isso a psicologia social poderia contribuir eficazmente, seja determinando os indivíduos mais adequados para as tarefas exigidas (processos de seleção), seja ajudando os indivíduos a se adaptarem às exigências e condições dessas tarefas (processo de formação, mediação de conflitos, "relações humanas"). (Martín-Baró, 1985/2015, pp. 34)
\end{abstract}

De acordo com Martín-Baró, nesse movimento de conversão pragmática, a teoria foi desprezada e interpretada como metafísica. Consolidou-se, por essa via, uma perspectiva ao mesmo tempo positivista e pragmatista da ciência psicológica que marcaria decisivamente o desenvolvimento da Psicologia Social. Floyd Allport (1890-1979), ao reduzir a Psicologia Social ao estudo do comportamento dos indivíduos em interação, teria sido o principal representante dessa perspectiva individualista, positivista e pragmatista. De acordo com Martín-Baró,

Com Allport (1924) aparece claramente a natureza da Psicologia Social norteamericana: a pretensão científica produz um reducionismo radical que elimina o social, enquanto a busca por respostas pragmáticas aos problemas da sociedade ianque resulta na priorização de fenômenos microssociais ou situações individuais, ignorando 
o contexto social mais amplo. O resultado é uma Psicologia Social positivista que não tem consciência de ou ignora os seus próprios pressupostos, que não enxerga a natureza histórica dos processos humanos e que, consequentemente, tende a converter em universais elementos e processos que são circunstanciais ou características típicas de ambientes norte-americanos. (Martín-Baró, 1985/2015, pp. 37)

Desse período, datariam também o surgimento do estudo dos grupos, a análise da formação e da mudança de atitudes e o aparecimento do estudo da personalidade, todos motivados pelas exigências postas, pela Segunda Guerra Mundial, às Forças Armadas e à indústria norte-americanas. Quanto ao estudo dos grupos, assim resumiu seu significado:

O estudo dos grupos era particularmente atrativo para os norte-americanos precisamente por seu interesse pela integração de diversos grupos étnicos em uma só e mesma sociedade. A guerra colocava problemas muito particulares sobre a integração dos indivíduos nas unidades militares e as consequências que as relações no interior desses grupos militares tinham em sua atuação e eficiência. Essa mesma pergunta sobre integração grupal e eficiência havia sido formulada diversas vezes na área industrial, demonstrando a convergência de interesses que potencializou o estudo dos primeiros grupos. (Martín-Baró, 1985/2015, pp. 37)

Seriam representativos, desse período, a sociometria de Jacob Moreno (1889-1974); o estudo sobre normas sociais de Muzafer Şerif (1906-1988), o programa de pesquisa sobre dinâmica de grupo de Kurt Lewin (1890-1947) e os trabalhos de Samuel A. Stouffer (19001960) que deram origem aos volumes da obra $O$ soldado americano. Veremos, adiante, como o autor ampliou essa lista em Sistema, grupo y poder. Antes, cumpre observar que o autor não apenas explorou os principais vetores desse período, como também teceu considerações sobre seu fim, ao resumir as limitações dos estudos que originaram a crise da "dinâmica de grupos". De acordo com o autor Martín-Baró,

Houve uma enorme difusão de modelos e estudos empíricos sobre os grupos. Todavia, a área da dinâmica de grupos como um todo tinha duas gravíssimas limitações que condicionaram negativamente seu desenvolvimento. Por um lado, o estabelecimento de paralelos com as ciências físico-químicas - tanto do ponto de vista teórico quanto do ponto de vista metodológico - resultou na redução das pesquisas sobre os grupos 
em pesquisas sobre os pequenos grupos. Na maior parte das vezes, adotava-se o pressuposto de que, apesar de pequenas variações, os grandes grupos são apenas versões ampliadas das microestruturas grupais. Outra limitação foi a adoção, desde o começo (ainda que não fosse de uma forma consciente), da perspectiva do poder estabelecido (social, industrial ou militar), o que fez com que a dinâmica de grupos fosse concebida como forças e processos que produziam a integração dos indivíduos nos grupos, mas não como forças e processos que poderiam fazer com que os indivíduos mudassem os grupos ou fazer com que certos grupos modificassem outros. Era uma perspectiva de adaptação individual e o seu pressuposto era de que, em caso de conflito, o indivíduo (não o grupo) deveria ser modificado. (Martín-Baró, 1985/2015, pp. 38)

Martín-Baró observou, ainda, que os outros dois campos de estudo abertos pela Segunda Guerra Mundial, a análise da formação e da mudança de atitudes e o estudo da personalidade, não tiveram destino muito diferente. Segundo ele, ambos teriam florescido e se multiplicado com a guerra, encontrando seus limites por volta da década de 1960. Em suma, o período teria sido marcado por três constantes: o individualismo, o psicologismo e a perspectiva do poder estabelecido. Para o autor,

No segundo período da Psicologia Social não houve apenas uma inclinação definitiva em favor de uma sociopsicologia, mas houve a opção por uma visão individualista, que aborda a realidade tomando o indivíduo como unidade de análise e como princípio epistemológico. Em outros termos, o social é visto e compreendido a partir do individual. Assim, boa parte da Psicologia Social da época margeou continuamente o psicologismo - enquanto alguns autores estiveram completamente mergulhados nele. Esse psicologismo, no último período, desembocou em um subjetivismo desenfreado, cuja semente já estava lançada nos trabalhos de dinâmica de grupos e sobre atitudes. Tudo isso ressalta ainda mais a terceira constante do período: a perspectiva do poder. O pressuposto implícito de que a sociedade é um dado prévio, um ponto de partida, resulta na ausência de questionamentos sobre ela. É o indivíduo quem deve se adaptar à estrutura social, militar ou industrial, não é a estrutura que deve mudar. Lamentavelmente, esta perspectiva permeou a maior parte dos trabalhos de Psicologia Social, fazendo deles instrumentos a serviço das necessidades do poder estabelecido: ajudando a mudar o indivíduo, a conter seus protestos e sua rebeldia, e 
fortalecendo a estrutura do sistema social capitalista, fundado na desigualdade e na exploração. (Martín-Baró, 1985/2015, pp. 40)

O terceiro período teria sido marcado pela seguinte questão: o que liberta as pessoas da desordem estabelecida? Nele, "o marco social é aceito como um dado, mas, precisamente, como um dado criticável em sua facticidade e em sua negação de possibilidades sociais distintas" (Martín-Baró, 1985/2015, p. 41). Daí porque, "mais importante do que saber como se dá a integração das pessoas à ordem social estabelecida, é saber como as pessoas podem mudar essa ordem, libertando-se de exigências e imposições e construindo uma ordem social diferente, mais justa e humana” (Martín-Baró, 1985/2015, p. 41).

Martín-Baró destacou três "revisões críticas" (1985, p. 41) que, segundo ele, teriam contribuído decisivamente para a formulação dessa nova questão: a visão da realidade social como construção, a partir da publicação do tratado de sociologia do conhecimento de Peter Berger (1929-2017) e Thomas Luckmann (1927-2016): A construção social da realidade (1966); a concepção da realidade social como conflitiva, desenvolvida a partir da teoria social marxiana; e a percepção do papel político da Psicologia Social, elaborada de maneira exemplar pela antipsiquiatria (Martín-Baró, 1985/2015, p. 43).

De acordo com Martín-Baró, esse é período em que se evidencia a determinação social do conhecimento e que, portanto, "aparece a necessidade de que o psicólogo social, como outros cientistas sociais, tome consciência de seu enraizamento social e, consequentemente, dos interesses históricos a que, por opção ou inconsciência, está a serviço” (Martín-Baró, 1985/2015, p. 44-45) ${ }^{4}$. Assim resumiu o autor a atitude fundamental desse terceiro período:

Ao não aceitar a realidade social como ponto de partida imutável, o problema central já não é tanto a relação entre indivíduo e sociedade, a adaptação ou inadaptação, mas a oposição entre grupos que gera uma ordem social concreta em cujo interior os indivíduos atualizam interesses, perspectivas e situações sociais distintas e conflitivas. (Martín-Baró, 1985/2015, pp. 46)

Essa é, enfim, a visão histórica apresentada por Martín-Baró no primeiro volume de sua Psicología Social desde Centroamerica. Acontece que, conforme antecipamos, as considerações martinbaronianas sobre a história da Psicologia Social não se esgotaram nesses trechos do primeiro capítulo de Acción y ideología. Conforme procuraremos mostrar nas 
páginas seguintes, Martín-Baró voltou a refletir sobre a história da Psicologia Social quando da redação de Sistema, grupo y poder, segundo volume de sua magnum opus.

\section{Uma Visão Histórica da Psicologia Social em Sistema, Grupo y Poder}

Anos mais tarde, ao sistematizar criticamente os conhecimentos acumulados pela Psicologia Social sobre os fenômenos grupais, Martín-Baró empreendeu uma rica análise da assim chamada "dinâmica de grupos", análise que o levou a identificar o otimismo da década de 1960 e o maio de 68 como o princípio e o fim dessa que foi, no segundo período de sua história, a fase de maior desenvolvimento da Psicologia Social.

Sistema, grupo y poder encontra-se dividido em cinco capítulos. No primeiro deles, dedicado ao exame da “desordem ordenada" (Martín-Baró, 1989/2014, p. 13) chamada sociedade, Martín-Baró refletiu sobre a categoria de sistema social a partir da apresentação de dois enfoques: o enfoque funcionalista, representado pela sociologia de Talcott Parsons (19021979), e o enfoque conflitivo, melhor representado, para o autor, pela teoria social de Karl Marx (1818-1883). O autor esmiuçou, ainda, o processo de constituição do sistema social a partir do tratado de sociologia de conhecimento de Peter Berger (1929-2017) e Thomas Luckmann (1927-2016): A construção social da realidade (1966), do qual já falara no primeiro volume, e teceu considerações sobre o processo de reprodução da ordem social a partir de uma reflexão sobre os conceitos de rotina e sobre a ideologia da cultura da pobreza. No segundo capítulo, partindo de uma distinção operada pelo psicólogo social espanhol Tomás Ibáñez e que remonta às reflexões de Michel Foucault (1926-1984), refletiu sobre a realidade e a natureza do poder, apresentando dois paradigmas empregados para sua elucidação: o paradigma jurídico-político e o paradigma estratégico. Com isso, examinou as principais interpretações sobre o fenômeno do conformismo, o que lhe permitiu avançar na compreensão do fenômeno de resistência ao poder social. No terceiro, no quarto e no quinto capítulos, refletiu sobre o significado de grupo, os principais enfoques psicossociais empregados em sua elucidação, esboçou uma teoria dialética sobre os grupos humanos e discutiu os principais aspectos dos grupos primários e funcionais.

Foi somente no quarto capítulo de Sistema, grupo y poder que Martín-Baró aportou novos elementos à sua "visão histórica da Psicologia Social". Ali, relacionou a importância concedida, na década de 1960, aos fenômenos de grupo, com o otimismo da primeira geração subsequente à Segunda Guerra Mundial. Segundo o autor Martín-Baró, 
A década de 60 foi, em muitos países, um período de efervescência social, de busca de mudanças profundas e de otimismo sobre a possibilidade de alcançá-las de um modo pacífico. Nesse momento, a primeira geração nascida depois da segunda guerra mundial chegava a sua maioridade e, superando o pessimismo existencialista que havia caracterizado os anos imediatamente anteriores e posteriores à guerra, ansiava por estabelecer novas formas de relação social cuja institucionalidade não eliminasse a liberdade individual e cuja eficiência produtiva não murchasse a realização peculiar de cada pessoa. (Martín-Baró, 1989/2014, pp. 229)

Na sequência, o autor identificou o "maio de 68" como o "momento climáctico da chamada dinâmica de grupos" (Martín-Baró, 1989/2014, p. 229), afirmando que esse período teria sido marcado por uma grande confiança quanto à possibilidade de explicar (e de transformar) a realidade macrossocial a partir das relações microssociais. De acordo com suas palavras,

Em Paris ou em Tóquio, em Frankfurt ou em Nova York, parecia dominar a confiança de que as mudanças pessoais que se produziam nos grupos pequenos poderiam irradiar por todo o social e mudar substancialmente a ordem imperante. Se vivia uma verdadeira explosão de liberdade individual e se acreditava que o conhecimento gerado na relação interpessoal, a razão encontrada na abertura de uns com os outros, teria a força necessária para reordenar as macroestruturas políticas e econômicas. Em outras palavras, acreditava-se que a liberdade gerada na transformação das células sociais menores provocaria a mudança do corpo social. (Martín-Baró, 1989/2014, pp. 229)

A metáfora orgânica não era ocasional. Na seção intitulada A célula social, MartínBaró buscou elucidar esse preconceito que levava a enxergar, nos pequenos grupos, o modelo para a compreensão da totalidade social ${ }^{5}$. Aqui, no entanto, o que importa destacar é a importância que Martín-Baró conferiu ao "Maio de 68" na configuração da atmosfera que deu lugar ao surgimento, ao desenvolvimento e à decadência da assim chamada "dinâmica de grupos". Afinal, para o autor,

"Maio de 68" foi um movimento antirracionalista de intelectuais universitários, uma dessas epidemias de irracionalismo que periodicamente se produzem no âmbito 
acadêmico como compensação ao império da lógica cotidiana. Em termos de classe, constitui um processo de natureza pequeno-burguesa, que não teve grande repercussão nos países do terceiro mundo. Claro, isso não o faz menos significativo ou valioso, mas o qualifica e o situa. Se tratava de uma mescla curiosa da "não diretividade" ou “centramento na pessoa” de Carl R. Rogers (1961), das técnicas grupais iniciadas por Kurt Lewin e da crítica freudomarxista da unidimensionalidade do sistema capitalista avançada por Herbert Marcuse (1965). (Martín-Baró, 1989/2014, pp. 229)

Buscando entender como seria possível "elementos tão diversos juntarem-se num mesmo recipiente" (Martín-Baró, 1989/2014, p. 230), o autor passou à descrição das teses fundamentais de Herbert Marcuse (1898-1979) e Carl Rogers (1902-1987). Após resumir a tese de Marcuse sobre o homem unidimensional e a proposta rogeriana de terapia centrada na pessoa, Martín-Baró sugeriu que essas duas determinações ideológicas encontraram vazão no conjunto de procedimentos desenvolvidos a partir dos trabalhos de Kurt Lewin. Assim sintetizou a conjunção histórico-concreta desses "elementos tão diversos” (Martín-Baró, 1989/2014, p. 230),

Nunca ficou muito claro em que consiste concretamente as tendências autoatualizantes postuladas por Rogers. No entanto, a proposta de um retorno a si mesmo, de um retorno à própria autenticidade, livre de repressões, parecia muito congruente com a demanda de libertação marcusiana, e foi acolhida com entusiasmo por vários grupos de jovens universitários. "Ser autêntico" se converteu em um horizonte fundamental do movimento juvenil. Para ele havia que eliminar as travas sociais que impediam o desenvolvimento de suas próprias potencialidades. Como dizia o slogan que fez sucesso, era necessário garantir que estava "proibido proibir". Nesse processo as técnicas de grupo desenvolvidas por Lewin ofereceram um meio adequado para o descobrimento de si mesmo e das pessoas entre si. (Martín-Baró, 1989/2014, pp. 231)

Para Martín-Baró, esse movimento teria produzido um otimismo que alçou a prática da assim chamada "dinâmica de grupos" a um patamar quase religioso. Segundo ele, "o diálogo em grupo chegou a constituir uma espécie de fé. Parafraseando a expressão evangélica, o grupo se convertia praticamente em caminho, verdade e vida." (Martín-Baró, 1989/2014, p. 231). Em seguida, Martín-Baró apontou os limites da "dinâmica de grupos" com base na análise do idealismo romântico do "maio de 68". No seu entendimento, as 
derrotas do movimento teriam servido para mostrar "a inviabilidade prática da mudança social a partir de pressupostos puramente pessoais" (Martín-Baró, 1989/2014, p. 231). Segundo ele,

A reação do sistema, embora moderada, não deixou de ser menos firme. Superado um primeiro momento de estupor, o mesmo aparato de controle social que o movimento juvenil tratava de 'extrojetar' do psiquismo pessoal e coletivo saiu à praça pública, sob a forma de repressão policial, e aos meios de comunicação massiva, na forma de contra-ataque ideológico. À "irracionalidade contestatória" dos jovens se opôs a racionalidade da lei estabelecida, e ao anarquismo de quem pretendia submeter tudo ao diálogo e debate se opôs a ordem sistemática dos cassetetes policiais. Mais uma vez a história confirmava os limites do idealismo e mostrou a inviabilidade prática da mudança social a partir de pressupostos puramente pessoais. 'Maio de 68' significou os limites da 'dinâmica de grupos', um feito que a psicologia social demorou ainda uns anos para compreender e que somente com a experiência traumática do Vietnã chegou a aceitar. Mas então optou debruçar-se na subjetividade das pessoas, como se a transformação social que não era capaz de ser realizada mediante à dinâmica de grupos poderia ser compensada pela transformação na percepção que as pessoas tinham da sociedade" (Martín-Baró, 1989/2014, pp. 231-232).

Martín-Baró também refletiu sobre os impactos de 1968 na América Latina. Observou que havia alguma semelhança com o otimismo desenvolvimentista da década de 1960. Conforme assinalou, "Embora o movimento que culminou no 'Maio de 68' não tenha produzido maior repercussão nos países da América Central, a década de sessenta foi também para estes uma época de otimismo social" (Martín-Baró, 1989/2014, p. 232). Fez questão de assinalar que, diferentemente do que se passou nos países centrais do capitalismo, na América Latina esse otimismo durou pouco, vitimado pela onda de ditaduras que assolou a maior parte dos países do continente. Mesmo assim, concluiu que esse otimismo foi o que propiciou o desenvolvimento da Psicologia na América Latina. Segundo Martín-Baró,

A "dinâmica de grupos" teve pouco ou nada a ver com esses processos sociopolíticos. Mas o clima de relativo otimismo social e progresso dos setores médios propiciou um período de desenvolvimento da psicologia latino-americana e sua crescente aceitação em diversos âmbitos da vida social até então fechados para sua contribuição. (MartínBaró, 1989/2014, pp. 232) 
Martín-Baró retomou, ainda, a importância de Kurt Lewin para a constituição da assim chamada "dinâmica de grupos". A esse respeito, assim se expressou:

Aparentemente, essa expressão (dinâmica de grupos) começou a ser usada em meados da década de 1930 e foi consagrada em 1944 por Kurt Lewin. Contudo, o princípio da dinâmica de grupo não se reduz a uns processos e técnicas, mas sim alude a todas aquelas forças que se produzem em qualquer grupo, pequeno ou grande, e que determinam tanto o que o grupo é e realiza, como o que são e realizam os indivíduos enquanto membros de um grupo. (Martín-Baró, 1989/2014, pp. 232)

O autor recorreu também ao trabalho de Roger Mucchieli (1919-1981) para apresentar as principais fontes da dinâmica de grupos. Reafirmou elementos já abordados em Acción y ideología, observando que a "dinâmica de grupos" teria surgido "a partir das necessidades políticas, industriais e militares dos Estados Unidos, assim como da evolução em si da psicologia e da sociologia" (Martín-Baró, 1989/2014, p. 233). Acrescentou que suas principais fontes estariam no estudo realizado por Elton Mayo na Western Electric Company; na psicoterapia de grupo praticada por médicos na Europa e Estados Unidos; na sociometria de Jacob Lévy Moreno; e nas abordagens e técnicas de Kurt Lewin (Martín-Baró, 1989/2014, p. 233). E, finalmente, encerrou sua incursão pela história da "dinâmica de grupos" apontando suas principais limitações e seu caráter ideológico, o que lhe permitiu concluir que,

Ao assumir implicitamente que o grupo pequeno constitui o paradigma da realidade grupal, [a "dinâmica de grupos"] deixa de lado tudo o que concerne ao confronto macrogrupal, tão difícil de captar da perspectiva positivista; e, ao privilegiar os aspectos dinâmicos dos processos frente aos aspectos estruturais, prescinde do sentido e papel sociais que cada grupo desempenha como parte de uma história. (Martín-Baró, 1989/2014, p. 234)

\section{Principais Aspectos da Visão Histórica da Psicologia Social de Ignacio Martín-Baró}

A leitura e a análise imanentes da "visão histórica da Psicologia Social" desenvolvida por Martín-Baró nos dois volumes de sua Psicología Social desde Centroamerica permitiunos constatar que, para ele, a história da Psicologia Social não deve ignorar a importância da 
reflexão filosófica para a pesquisa histórica; deve reconhecer a importância dos clássicos da teoria social e política; pressupõe o vínculo dialético entre reflexões filosóficas e crises sociais e que estas representaram esforços na direção da resolução de tais crises; encontra-se dialeticamente subordinada à história social e política; não conhece um desenvolvimento linear e cumulativo; permite a justaposição de teorias oriundas de problemáticas distintas; insere-se no movimento mais geral que determinou o surgimento das ciências humanas e sociais; supõe um movimento prévio de crítica e de libertação da Psicologia, e que esse movimento pressupõe, por sua vez, o recurso à história e uma nova compreensão da história da Psicologia Social; deve assumir a perspectiva dos oprimidos se deseja contribuir para seu processo de emancipação; deve manter uma relação crítica com a perspectiva positivista e pragmatista da ciência psicológica que hegemonizou a Psicologia Social a partir de seu processo de "americanização"; deve, da mesma forma, criticar o individualismo, o psicologismo, o subjetivismo e o elitismo; não pode partir de uma compreensão limitada do conceito de crise, jamais a encarando como algo negativo ou improdutivo, mas, sim, contraditório e, portanto, igualmente produtivo, portador da possibilidade de redenção da Psicologia diante de seu passado de compromisso com as classes dominantes.

Acrescentamos que, ao apresentar “uma visão histórica da Psicologia Social”, MartínBaró demonstrou o mesmo cuidado expresso no subtítulo de sua magnum opus. Afinal, conforme observou Lacerda Jr. (2018, p. 72), ao propor uma Psicologia Social desde a América Central, Martín-Baró mostrou não possuir a pretensão de edificar uma Psicologia Social sobre ou para a América Central, mas de construí-la desde ou a partir da realidade centro-americana. Além disso, destacamos dois pontos: primeiramente, que a proposta de periodização martinbaroniana revela-nos sua compreensão profundamente materialista e dialética da história, em que as teorias e práticas psicossociais são compreendidas não como o produto de individualidades abstratas, mas como respostas sociais a questões historicamente determinadas; em segundo lugar, que sua "visão histórica" não incorre no equívoco (compartilhado por positivista e relativistas) de opor, formal e abstratamente, ciência e política, demonstrando que o autor possuía consciência de que a objetividade nas ciências humanas e sociais contradiz o reconhecimento e a adoção de determinada posição de classe.

\section{Considerações Finais}

Ignacio Martín-Baró viu de perto as lutas populares nas décadas de 1970 e 1980. Acompanhando o movimento real da história, buscou produzir uma Psicologia Social que 
pudesse contribuir para a emancipação das amplas maiorias populares latinoamericanas. Com esse objetivo, empreendeu um enorme esforço de crítica, inventariando a Psicologia de seu tempo e procurando explicitar seus pressupostos ideológicos e sociomateriais. Essa crítica levou-o a produzir uma interpretação original da história da Psicologia Social. Primeiramente, expôs sua "visão histórica da Psicologia Social" no primeiro capítulo de Acción y ideología. Anos mais tarde, em Sistema, grupo y poder, avançou no exame desse que foi o período de maior vigor e entusiasmo da Psicologia Social: a fase de surgimento da assim chamada "dinâmica de grupos". Sua rica interpretação permanece, porém, muito pouco conhecida, sobretudo entre estudantes de Psicologia de língua portuguesa, favorecendo a perpetuação de interpretações limitadas da história da Psicologia Social. Desejamos, com essa modesta contribuição, auxiliar na reversão desse quadro, na esperança de contribuirmos, por pouco que seja, para a ampliação do conhecimento a respeito da interpretação martinbaroniana da história da Psicologia Social e para os ainda escassos estudos de sua obra no Brasil.

\section{Referências}

Costa, G. M. (2009). Contribuição da análise imanente à pesquisa de textos. Revista Arma da Crítica, 1(1), 24-33. Recuperado de http://www.armadacritica.ufc.br/phocadownload/gilmaisa.pdf

De La Corte, L. (2001). Memoria de un compromiso: La psicología social de Ignacio MartínBaró. Bilbao, Espanha: Desclé du Brouwer.

Dobles, I. (2016). Ignacio Martín-Baró: Una lectura en tiempos de quiebres y esperanzas. San José, Costa Rica: Arlekín.

Freedman, J. L., Carlsmith, J. M., \& Sears, D. O. (1977). Psicologia Social (3a ed., A. Cabral, Trad.). São Paulo: Cultrix.

Hilgard, E. R., Leary, D. E., \& McGuire, G. R. (1998). A história da psicologia: Um panorama e avaliação crítica. In J. Brožek, \& M. Massimi (Orgs.), Historiografia da Psicologia Moderna - versão brasileira (pp. 399-432). São Paulo: Loyola.

Lacerda Jr., F. (Org.). (2017). Colocando a Psicologia contra a ordem: Introdução aos escritos de Ignacio Martín-Baró. In I. Martín-Baró, Crítica e libertação na psicologia (pp. 721). Petrópolis: Vozes.

Lacerda Jr., F. (2018). Historicizar para libertar: A proposta de psicologia da libertação. In F. T. Portugal, C. Facchinetti, \& A. C. Castro (Org.), História social da Psicologia (pp. 55-81). Rio de Janeiro: Nau. 
Lacerda Jr., F. (2010). Psicologia para fazer a crítica? Apologética, individualismo e marxismo em alguns projetos psi (Tese de Doutorado). Pontifícia Universidade Católica de Campinas, Programa de Pós-Graduação em Psicologia, Campinas, SP, Brasil. Recuperado de http://tede.bibliotecadigital.puccampinas.edu.br:8080/jspui/handle/tede/422

Lane, S. T. M., \& Freitas, M. F. Q. (1997). Processo grupal na perspectiva de Ignácio MartínBaró. Revista Interamericana de Psicología, 31(2), 293-308. Recuperado de https://dialnet.unirioja.es/servlet/articulo?codigo $=3852748$

Lessa, S. (2014). Um pouco de técnica. In S. Lessa, O revolucionário e o estudo: Por que não estudamos? (pp. 67-76). São Paulo: Instituto Lukács.

Lindzey, G., \& Aronson, E. (Eds.). (1968). Handbook of Social Psychology (2a ed.). Reading, Massachusetts: Addison-Wesley.

Lindzey, G., \& Aronson, E. (Eds.). (1985). Handbook of Social Psychology. (3a. ed.). Lawrence Erlbaum Associates.

Martín-Baró, I. (2015). Acción y ideología: Psicología social desde centroamérica (Vol. 1, 2a ed., 17a reimp.). São Salvador: UCA Editores. (Obra original publicada em 1985)

Martín-Baró, I. (2014). Sistema, grupo y poder: Psicología social desde centroamérica (Vol. 2, $1^{\text {a }}$ ed., $6^{\text {a }}$ reimp.) São Salvador: UCA Editores. (Obra original publicada em 1989)

Martín-Baró, I. (1992). Los grupos con historia: Um modelo psicosocial. Revista de Psicología de El Salvador, 11(43), 7-29. Recuperado de http://www.uca.edu.sv/coleccion-digital-IMB/articulo/los-grupos-con-historia-unmodelo-psicosocial/

Martín-Baró, I. (1996). Writings for a Liberation Psychology. Cambridge, Massachussetts: Harvard University Press.

Martín-Baró, I. (2017). Crítica e libertação na psicologia (F. Lacerda Jr., Trad.). Petrópolis: Vozes.

Martins, S. T. F. (2003). Processo grupal e a questão do poder em Martín-Baró. Psicologia \& Sociedade, 15(1), 201-217. doi: 10.1590/S0102-71822003000100011

\section{Endereço para correspondência}

\section{Filipe Boechat}

Rua Bartolomeu Portela, 10, 401, Botafogo, Rio de Janeiro - RJ. Brasil. CEP 22290-190

Endereço eletrônico: filipeboechat@ufrj.br 


\section{André Vieira}

Largo dos Leões, 8, 204, Humaitá, Rio de Janeiro - RJ, Brasil. CEP 22260-210

Endereço eletrônico: andre.asvieira@gmail.com

\section{Bruno Pizzi}

Rua Monte Alegre, 194, 102, Santa Teresa, Rio de Janeiro - RJ, Brasil. CEP 20240-193

Endereço eletrônico: brunopizzi@ufgd.edu.br

Recebido em: 01/10/2019

Reformulado em: 24/04/2020

Aceito em: 03/06/2020

\section{Notas}

* Professor Adjunto da Universidade Federal do Rio de Janeiro (UFRJ) e coordenador do Grupo de Extensão Popular Ignacio Martín-Baró.

** Professor do Uni IBMR, membro do GT de História Social da Psicologia da Associação Nacional de Pesquisa e Pós-graduação em Psicologia (ANPEPP) e do Grupo de Extensão Popular Ignacio Martín-Baró.

*** Professor Adjunto da Universidade Federal da Grande Dourados (UFGD) e membro do Grupo de Extensão Popular Ignacio Martín-Baró.

${ }^{1}$ Embora os artigos de Lane e Freitas (1997) e Martins (2003) tomem Sistema, grupo y poder (1989) como referência fundamental, o objetivo das autoras difere bastante do nosso, razão pela qual não há, nesses artigos, qualquer menção à “visão histórica da Psicologia Social” desenvolvida por Ignacio Martín-Baró.

${ }^{2}$ Os dois capítulos seguintes, A natureza social do ser humano e As estruturas sociais e seu impacto psicológico, revelam a preocupação do autor em evidenciar seus pressupostos no que diz respeito à compreensão do ser social. Nos cinco capítulos restantes, o autor realiza uma revisão crítica dos principais temas da Psicologia Social: socialização; categorização e estereótipos; atitudes; cooperação; agressão.

${ }^{3}$ Todas as citações das obras de Ignacio Martín-Baró foram livremente traduzidas. As citações extraídas de Sistema, grupo y poder contaram com a generosa contribuição de Clara Garcia, a quem agradecemos.

${ }^{4}$ Ao que parece, essa tomada de consciência seria, para Martín-Baró, um processo irreversível. Assim, ignorar o enraizamento social da Psicologia só seria possível mediante uma atitude cínica. E o que sugere a afirmação do autor de que "quem se entrincheira em sua negação da opção consciente sabe que, de fato, serve àqueles para o qual o poder opera, isto é, à classe dominante em cada sociedade, e isto não somente nas aplicações práticas do seu quefazer, mas, fundamentalmente, na estruturação mesma de seu saber e fazer científicos” (Martín-Baró, 1985/2015, pp. 44-45).

${ }^{5}$ No terceiro capítulo, onde apresentou seu modelo dialético e psicossocial para a compreensão dos processos grupais (Martín-Baró, 1989/2014, pp. 229 e ss.), Martín-Baró chamou esse preconceito de parcialismo paradigmático. Segundo o autor, trata-se da tendência a se tomar a parte pelo todo e, portanto, de explicar a vida social a partir da estrutura e da dinâmica de grupos sociais bastante particulares, como a família ou os T-groups.

Este artigo de revista Estudos e Pesquisas em Psicologia é licenciado sob uma Licença Creative Commons Atribuição-Não Comercial 3.0 Não Adaptada. 